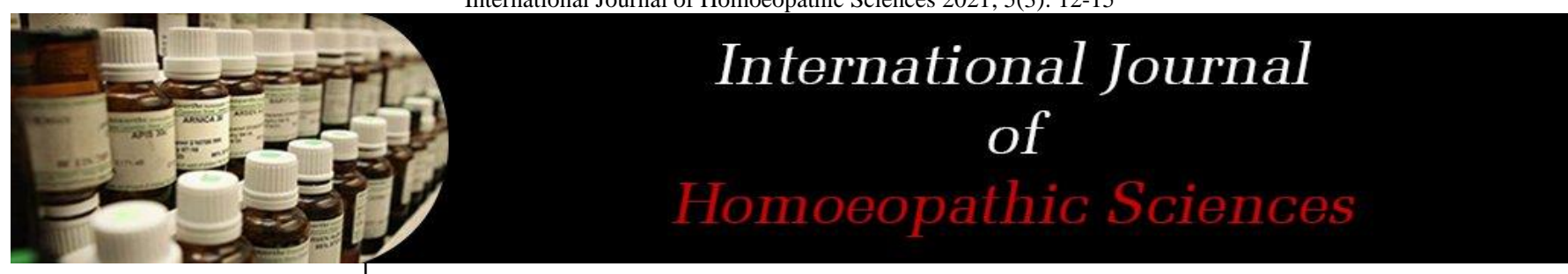

E-ISSN: $2616-4493$

P-ISSN: 2616-4485

www.homoeopathicjournal.com IJHS 2021; 5(3): 12-15

Received: 10-05-2021

Accepted: 12-06-2021

Dr. Vaishali Shinde Ministry of AYUSH, Government of India, Regional Research Institute for Homoeopathy, Under Central Council for Research in Homoeopathy, Ministry of AYUSH, Govt. of India

Dr. Ramesh Bawaskar Ministry of AYUSH, Government of India, Regional Research Institute for

Homoeopathy, Under Central

Council for Research in

Homoeopathy, Ministry of AYUSH, Govt. of India
Corresponding Author: Dr. Vaishali Shinde Ministry of AYUSH, Government of India, Regional Research Institute for Homoeopathy, Under Central Council for Research in Homoeopathy, Ministry of AYUSH, Govt. of India

\section{Homoeopathy in cervicitis: A review}

\author{
Dr. Vaishali Shinde and Dr. Ramesh Bawaskar
}

DOI: $\underline{\text { https://doi.org/10.33545/26164485.2021.v5.i3a.396 }}$

\begin{abstract}
Cervicitis is very common and characterized by an inflammation of the mucosa and sub mucosa of the cervix. Most often the bacterial and viral infections that cause Cervicitis are transmitted by sexual contact. Cervicitis is associated with Chlamydia trachomatis, Neisseria gonorrhoeae as the commonest cause, with Trichomonas vaginalis, herpes simplex virus, and Mycoplasma genitalium also as etiologic agents or conditions. Cervicitis that's caused by gonorrhea or Chlamydia can spread to the uterine lining and the fallopian tubes, resulting in pelvic inflammatory disease (PID), an infection of the female reproductive organs that can cause fertility problems if left untreated. Antibiotics are prescribed for STIs with the drug resistance causing a major threat. Homeopathic literature has abundance of literature on the medicines that can be used for Cervicitis. Though there are a few studies showing the role of homoeopathic medicines in treatment Cervicitis there is a dearth of clinical studies depicting role of homoeopathic medicines in treating Cervicitis. Future observational studies and randomized control trials are suggested to ascertain the efficacy of homoeopathy in treatment of Cervicitis.
\end{abstract}

Keywords: cervicitis, homoeopathy, neisseria gonorrhoeae, sexually transmitted infection

\section{Introduction}

Cervicitis is characterized by an inflammation of the mucosa and sub mucosa of the cervix which frequently results from a sexually transmitted infection, such as Chlamydia or gonorrhea. Acute Cervicitis is defined as the presence of yellow cervical mucopus or an increased number of polymorphonuclear leucocytes (PMNs) in cervical mucus ${ }^{[1,2]}$.

Cervicitis is very common. It affects more than one half of all women at some point during their adult life. Each year, there are an estimated 357 million new infections with 1 of 4 STIs: Chlamydia, gonorrhoea, syphilis and trichomoniasis. More than 1 million sexually transmitted infections (STIs) are acquired every day worldwide. Drug resistance, especially for gonorrhoea, is a major threat to reducing the impact of STIs worldwide ${ }^{[3,4]}$

Most often, the bacterial and viral infections that cause Cervicitis are transmitted by sexual contact. Cervicitis is associated with Chlamydia trachomatis, Neisseria gonorrhoeae as the prime etiologic suspects, with Trichomonas vaginalis, herpes simplex virus, and Mycoplasma genitalium also as etiologic agents or conditions. The ectocervical squamous epithelium an extension of the vaginal epithelium becomes inflamed by the same microorganisms that are responsible for vaginitis i.e., Trichomonas, Candida, and HSV. Conversely, Chlamydia trachomatis and Neisseria gonorrhoeae infect only the glandular epithelium, both of which are transmitted sexually. An allergy to contraceptive spermicides, latex in condoms may lead to Cervicitis. A device inserted such as a cervical cap, diaphragm, IUD, or pessary, also can cause Cervicitis. An overgrowth of some of the bacteria that are normally present in the vagina (bacterial vaginosis) can lead to Cervicitis ${ }^{[4-6]}$. The combined population attributable risk $\%$ of these pathogens is only $18 \%$, suggesting other factors are involved ${ }^{[7]}$. Among all the females diagnosed as vaginal discharge syndrome or Cervicitis, a very small percentage actually turned out to be positive upon laboratory testing for bacterial vaginosis, trichomoniasis, candidiasis, gonorrhoea and Chlamydia infection ${ }^{[8]}$. Etiologic factors have not been identified in many women with cervicitis ${ }^{[9]}$. The various risk factors include Age younger than 24, Low socioeconomic status, Multiple sex partners, Unmarried status, H/0 Sexually Transmitted Disease ${ }^{[1,5,10]}$.

Cervicitis is asymptomatic in about $75 \%$ of cases. If symptoms are present, these may include large amounts of unusual vaginal discharge, Frequent, painful urination, pain during intercourse, bleeding between menstrual periods, Vaginal bleeding after intercourse, not associated with a menstrual period. On examination the cervix may appear eroded and friable (strawberry-appearing) with a yellow-green mucopurulent discharge present in the 
endocervical canal. Gram staining reveals more than 10 polymorphonuclear leukocytes per oil immersion field ${ }^{[1,2 \text {, }}$ 5].

\section{Diagnosis}

The diagnosis can be established by the finding of more than 10 PMNs per 1,000x microscopic field. Nucleic acid amplification testing (NAAT) is recommended for $\mathrm{C}$. trachomatis and N. gonorrhoeae. Cell culture, Antigen and direct nucleic acid detection and DNA probe tests are helpful. A culture specimen should be obtained by swabbing the endocervix. Nonculture techniques using direct visualization of Chlamydia organisms following staining with fluorescein-labeled antibodies or immunohistochemical staining techniques provide quicker, cheaper results. DNA amplification testing are a simple, accurate, and reliable method for identifying Chlamydia infections even in lowprevalence, asymptomatic patients. Rarely, biopsy of the cervix is necessary ${ }^{[1,2]}$.

There is a need for including Papanicolaou smear for evaluation of vaginal discharge, as it helps establish the etiology of vaginal discharge reliably and provides a valuable opportunity to screen for cervical malignancies [11, 12]. Premalignant and malignant lesions of cervix are not uncommon in female complaints like vaginal discharge, post-coital bleeding, inter-menstrual bleeding, dyspareunia, and pain lower abdomen and can be diagnosed early by Pap smears ${ }^{[13]}$.

\section{Complications}

Cervix acts as a barrier to keep bacteria and viruses from entering your uterus. When the cervix is infected, there's an increased risk that the infection will travel into your uterus. Cervicitis that's caused by gonorrhea or Chlamydia can spread to the uterine lining and the fallopian tubes, resulting in pelvic inflammatory disease (PID), an infection of the female reproductive organs that can cause fertility problems if left untreated. Cervicitis can also increase the risk of a woman getting HIV from an infected sexual partner ${ }^{[5]}$.

In HIV infected females Cervicitis increases cervical HIV shedding. Treatment of Cervicitis in women with HIV infection reduces HIV shedding from the cervix and might reduce HIV transmission to susceptible sex partners. Chlamydia Cervicitis has the potential for serious complications in pregnancy, including pelvic inflammatory disease, infertility and ectopic pregnancy. In the pregnant patient, this infection is associated with premature rupture of membranes and increased fetal morbidity and mortality. In addition, infants infected by passage through an infected cervix are at risk for respiratory complications and conjunctivitis ${ }^{[14,15]}$.

\section{Prevention}

To reduce your risk of Cervicitis from sexually transmitted infections condoms are advised. To minimize transmission and reinfection, women treated for Cervicitis should be instructed to abstain from sexual intercourse until they and their partner(s) have been adequately treated and symptoms have resolved. Women who receive a diagnosis of Cervicitis should be tested for HIV and syphilis ${ }^{[5,14]}$.

\section{Treatment}

Successful treatment of Cervicitis involves treating the underlying cause of the inflammation. Cervicitis caused by an allergic reaction to products such as spermicide or feminine hygiene products need no treatment except for avoiding its use. Conventionally Cervicitis caused by a sexually transmitted infection (STI) will need treatment for both partners, often with an antibiotic medication. Antibiotics are prescribed for STIs such as gonorrhea, Chlamydia. Cervicitis is commonly associated with Bacterial Vaginosis which, if not treated concurrently, leads to significant persistence of the symptoms and signs of Cervicitis ${ }^{[5,6]}$.

Chronic non-gonococcal non-chlamydial cervicitis is a condition of unknown etiology. Non-gonococcal nonchlamydial cervicitis is a condition that can cause unremitting symptoms. Most patients will respond to antibiotics, although other treatments including surgery may be necessary ${ }^{[16]}$.

\section{Homoeopathic management}

Studies indicate a positive role of homoeopathic therapy in the clinical management of chronic Cervicitis and cervical erosion [17]. Classic homeopathy has proven to treat candidiasis though with lesser affectivity compared to itraconazole ${ }^{[18]}$. A study suggests that when Homoeopathic medicine selected on basis of individualization, it gives permanent improvement without recurrences in leucorrhoea [19].

A case report depicted positive results of individualized Homoeopathic medicine Calcarea Carbonicum in treatment of Pelvic Inflammatory Disease ${ }^{[20]}$.

Homoeopathic literature suggests medicines for Cervicitis. In homoeopathic literature sixteen medicines have been given under cervicitis ${ }^{[21]}$. Nineteen remedies are indicated for Gonorrhoeae, and purulent staining yellow leucorrhoea have thirty five remedies enlisted ${ }^{[22]}$. Table- 01 shows frequently prescribed medicines for Cervicitis with their indications ${ }^{[22,23]}$ enlisted from experiences, research papers and text books. 
Table 1: Homoeopathic medicines for cervicitis with indications

\begin{tabular}{|c|c|}
\hline Medicine & \\
\hline Sepia & $\begin{array}{l}\text { Leucorrhoea yellow, greenish, with much itching. Violent stitches upward in the vagina, from uterus to umbilicus. Vagina } \\
\text { painful, especially on coition. Prolapse of uterus \& vagina. Menses too late \& scanty, irregular: early \& profuse: sharp } \\
\text { clutching pains. Pelvic organs relaxed. Bearing down sensation as if everything escapes through vulva. Must crossed limbs to } \\
\text { prevent protrusion, or press against vulva. }\end{array}$ \\
\hline Pulsatilla & $\begin{array}{l}\text { Leucorrhoea acrid, burning, creamy. Amenorrhea. Suppressed menses from wet feet, nervous debility, or chlorosis. Tardy } \\
\text { menses. Too late, scanty, thick, dark, clotted, changeable, intermittent. Pain in back, tired feeling. Diarrhea during or after } \\
\text { menses. }\end{array}$ \\
\hline Kreosote & $\begin{array}{l}\text { Leucorrhoea yellow, acrid; odour of green corn; worse between periods. Corrosive itching within vulva, burning \& swelling } \\
\text { of labia: Violent itching between labia \& thighs. Hemorrhage after coition. During menses, difficult hearing; buzzing \& } \\
\text { roaring. Burning \& soreness in external and internal parts. Menses too early, prolonged. Menstrual flow intermits; ceases on } \\
\text { sitting or walking; reappears on lying down. Pain worse after menses. Lochia offensive; intermits. }\end{array}$ \\
\hline Borax & $\begin{array}{r}\text { Leucorrhoea like white of eggs, with sensation as if warm wate } \\
\& \text { pain in stomach extending into small of back. Membranous } \\
\text { distension in clitoris with stickin }\end{array}$ \\
\hline Alumina & $\begin{array}{l}\text { Menses too early, short, scant } \\
\text { burning, running down to }\end{array}$ \\
\hline Bovista & $\begin{array}{r}\text { Leucorrhoea acrid, thick, tough, greenish, following } \mathrm{m} \\
\text { during menses. Menses too early \& profuse, worse at } \mathrm{n} \\
\text { Soreness of pubes during } \mathrm{r}\end{array}$ \\
\hline Nit Acid & $\begin{array}{l}\text { Leucorrhoea brown, flesh colored, watery, or stringy, offensive. External parts sore, wit } \\
\text { Uterine Hemorrhages, Menses early, profuse, like muddy water. With pain in back, hips } \\
\text { Metrorrhagia after parturition. }\end{array}$ \\
\hline Thuja & $\begin{array}{r}\text { Profuse leucorrhoea; thick, greenish. Severe pain in } \\
\text { gonorrhoea, salpingitis. Warty excrescences on vulva } \\
\text { Ovaritis; worse left side, at every me }\end{array}$ \\
\hline Merc & $\begin{array}{l}\text { Menses profuse, with abdominal pains. Leucorrhoea excoriating, greenish \& bloody; sensation of rawness in parts. Stinging } \\
\text { pain in ovaries. Itching \& burning; worse, after urinating; better, washing with cold water Mammae painful \& full of milk at } \\
\text { menses. }\end{array}$ \\
\hline Calc Carb & $\begin{array}{l}\text { Leucorrhoea, milky. Burning \& itching of parts before \& after menstruation; in little girls. Increased sexual desire; easy } \\
\text { conception. Before menses, headache, colic, chilliness \& leucorrhoea. Cutting pains in uterus during menstruation. Menses } \\
\text { too early, too profuse, too long, the least excitement causes their return. Uterus easily displaced. Much sweat about external } \\
\text { genitals. Sterility with copious menses. Uterine polypi. }\end{array}$ \\
\hline Kali & Yellow, tenacious leucorrhoea. Pruritus of Vulva, with great burning \& e \\
\hline Hydrastis & $\begin{array}{r}\text { Pruritus vulve, with profuse leucorrhoea. Erosion, excoriation of cervix. Leucorrhoea } \\
\text { Shreddy, tenacoius. Menorrhagia. Sexual exciten }\end{array}$ \\
\hline Arsenic & $\begin{array}{l}\text { Leucorrhoea acrid, burning, offensive, thin Menses too profuse and too soon. Burning in ovarian region. Pain as from red- } \\
\text { hot wires; worse-least exertion; causes great fatigue; better in warm room. Menorrhagia. Stitching pain in pelvis extending } \\
\text { down the thigh. }\end{array}$ \\
\hline
\end{tabular}

\section{Conclusion}

Cervicitis being very common with more than one half of all women being affected during their adult life with more than 1 million STIs acquired every day worldwide. Drug resistance is a major threat to reducing the impact of STIs worldwide. Homeopathic literature has abundance of literature on the medicines that can be used for Cervicitis. There is a lack of clinical studies depicting role of homoeopathic medicines in treating Cervicitis. Future observational studies and randomized control trials are suggested to ascertain the efficacy of homoeopathy in treatment of Cervicitis.

\section{References}

1. Fortner Kimberly B, Szymanski Linda M, Fox Harold E, Wallach Edward E. "Johns Hopkins Manual of Gynecology and Obstetrics", 3rd Edition, Lippincott Williams \& Wilkins 2007.

2. Gibbs Ronald S, Karlan Beth Y, Haney Arthur F, Nygaard Ingrid E. "Danforth's Obstetrics and Gynecology", 10th Edition, Lippincott Williams \& Wilkins 2008.

3. World Health Organization - Sexually transmitted infections (STIs) Fact sheet 2016. Available at https://www.who.int/news-room/factsheets/detail/sexually-transmitted-infections-(stis)
4. "Cervicitis: Medline Plus Medical Encyclopedia". Medlineplus.gov. U.S. National Library of Medicine. Retrieved 19 January 2019 Medline Plus Encyclopedia Cervicitis.

5. "Symptoms and causes - Mayo Clinic". www.mayoclinic.org. Mayo Clinic. Retrieved 7 January 2019.

6. Berek, Jonathan S. "Berek \& Novak's Gynecology", 14th Edition Lippincott Williams \& Wilkins 2007.

7. Lusk MJ, Garden FL, Rawlinson WD, Naing ZW, Cumming RG, Konecny P. Cervicitis aetiology and case definition: a study in Australian women attending sexually transmitted infection clinics. J Obstet Gynaecol Res 2016;42(2):148-57.

doi: 10.1111/jog.12880. Epub 2015 Dec 3. 107.

8. Vidyalaxmi Chauhan, Maitri Shah, Sejal Thakkar, Sangita Patel V, Yogesh Marfatia. Sexually transmitted infections in women: A correlation of clinical and laboratory diagnosis in cases of vaginal discharge syndrome Indian Dermatol Online J 2014;5(Suppl 1):S1-S5. doi: 10.4103/2229-5178.144498

9. Marrazzo JM, Martin DH. Management of women with cervicitis Clin Infect Dis 2007;44(Suppl 3):S102-10.

10. Efosa OB, Uwadiegwu AP. Cytopathological Examination and Epidemiological Study of Cervicitis in Commercial Sex Workers (CSWs) in Coal City 
(Enugu), Nigeria. J Infect Dis 2016;213(11):1828-35. doi: 10.1093/infdis/jiw025. Epub 2016 Jan 17. 105.

11. Sivaranjini R, Jaisankar T, Thappa DM, Kumari R, Chandrasekhar L, Malathi M1 et al. Spectrum of vaginal discharge in a tertiary care setting. Trop Parasitol 2013;3(2):135-9. doi: 10.4103/2229-5070.122140.

12. Salih MM, AlHag FTES, Khalifa MA, El Nabi AH. Cervical cytopathological changes among women with vaginal discharge attending teaching hospital. J Cytol 2017;34(2):90-94. doi: 10.4103/JOC.JOC_214_15.

13. Bal MS, Goyal R, Suri AK, Mohi MK. Detection of abnormal cervical cytology in Papanicolaou smears. J Cytol 2012;29(1):45-7. doi: 10.4103/0970-9371.93222.

14. "Diseases Characterized by Urethritis and CervicitisSTD Treatment Guidelines" 2015. www.cdc.gov. Retrieved 2019-01-19. https://www.cdc.gov/std/tg2015/urethritis-andcervicitis.htm\#treatment

15. Majeroni BA. Chlamydial cervicitis: complications and new treatment options. Am Fam Physician 1994;49(8):1825-9, 1832.

16. Mattson SK, Polk JP, Nyirjesy P. Chronic Cervicitis: Presenting Features and Response to Therapy. J Low Genit Tract Dis 2016;20(3):e30-3. doi: 10.1097/LGT.0000000000000225.

17. CCRH, Clinical evaluation of the homoeopathic medicines in chronic cervicitis and cervical erosion - A clinical study: A multicentric open clinical trial conducted by CCRH. Indian Journal of Research in Homoeopathy Year 2007;1(1):24-28.

18. Witt A, Kaufmann U, Bitschnau M, Tempfer C, Ozbal A, Haytouglu E et al. Monthly itraconazole versus classic homeopathy for the treatment of recurrent vulvovaginal candidiasis: a randomised trial. BJOG 2009;116(11):1499-505.

doi: 10.1111/j.1471-0528.2009.02262.x. Epub 2009 Jul 7.

19. Dr. Vivek Gupta, Dr. Pranav Shah. Utility Of Pulsatilla Nigrican And Sepia In Leucorrhoea: Utility Of Pulsatilla Nigrican And Sepia In Leucorrhoea. National Journal of Integrated Research in Medicine 2021;12(1):85-90.

20. Pandey S, Pandit RK. Pelvic inflammatory disease treated with homoeopathic medicine Calcarea carbonica: A case Report. Indian J Res Homoeopathy 2020;14:287-92.

21. Murphy R. Homeopathic medical repertory, 2nd revised edition, B. Jain Publishers.

22. Boericke W. Boericke's New Manual of Homoeopathic Materia Medica with Repertory: Third Revised \& Augmented Edition based on Ninth Edition. New Delhi: B. Jain Publishers 2010.

23. Allen HC. Allen's Keynotes-Rearranged and classified with leading remedies of the materia medica and bowel nosodes. 10th Reprint edition. B. Jain Publishers (P) Ltd 2006. 